\title{
Letter from New Zealand
}

\section{The New Zealand cervical cancer study: Could it happen again?}

\author{
Charlotte Paul
}

For one entire year in New Zealand a judicial inquiry has been under way into the treatment of carcinoma in situ of the cervix at the National Women's Hospital in Auckland. The National Women's is the teaching hospital for the Auckland University School of Medicine's department of obstetrics and gynaecology and the Postgraduate School of Obstetrics and Gynaecology. The inquiry was set up after a magazine article, entitled "An 'unfortunate experiment' at National Women's," alleged that an experimental research programme had been undertaken at the hospital entailing the study of the natural course of carcinoma in situ of the cervix by withholding conventional treatment from some patients. The authors of the article further alleged that an internal inquiry, set up after criticisms of the programme by two hospital doctors, had been a "white wash" and that there was no evidence that the research and the withholding of conventional treatment had ever formally ceased.

These allegations resulted in the setting up of a committee of inquiry led by one woman, Judge Silvia Cartwright. At the public hearings further claims were made. Among these were that vaginal smears had been taken from over 2000 new-born babies, as part of the same research, apparently without the knowledge or consent of their mothers; that a randomised controlled trial of treatment for invasive cervical cancer had been undertaken without the consent of patients; that groups of students had carried out vaginal examinations of anaesthetised women without their consent; and that postgraduate students had inserted and removed intrauterine devices on anaesthetised women before hysterectomy.

The public hearings started in August 1987 and continued until January 1988. The judge's report was released on 5 August 1988. ${ }^{2}$ I served as one of the three medical advisers to Judge Cartwright. I believe that the ethical issues raised by the inquiry go beyond the specific difficulties in one institution to the underlying problem of accountability in medicine. Indeed, the study at the centre of the inquiry was widely known to gynaecologists beyond New Zealand; yet only one attempted to intervene.

\section{The allegations}

The investigations leading to the magazine publication were made by two feminists: one a journalist (Coney), the other an academic in the area of women's studies (Bunkle). The starting point for their investigation was the paper "The invasive potential of carcinoma in situ of the cervix," recording the apparent outcome of the study, written by McIndoe et al and published in 1984. ${ }^{3}$ Two of the authors, McIndoe and McLean, were the doctors who had criticised the programme in 1973. The authors reported on 948 patients with carcinoma in situ of the cervix diagnosed histologically between 1955 and 1976 who were followed for five to 28 years. One group of patients continued to produce abnormal cytological results consistent with cervical neoplasia after initial diagnosis or treatment. Among this group of 131 women, 29 $(22 \%)$ subsequently developed invasive cancer of the cervix or vaginal vault. Among the other 817 women who had normal cytological results on follow up 12 $(1 \cdot 5 \%)$ developed invasive cancer.

Coney and Bunkle alleged in their article that these results were part of the findings in a study initiated by associate professor Herbert Green in the mid-1960s, which entailed following women with abnormal cytological findings after a diagnosis of carcinoma in situ. Some cases were diagnosed by colposcopically directed punch biopsy and the women were then offered no further treatment. Other women who had abnormal smears after cone biopsy or hysterectomy were alleged to have also received no further treatment. Coney and Bunkle claimed that there was no intention to cure these patients. The story of one woman, who had been a patient at the National Women's Hospital from 1964 to 1979 , was outlined. This woman had a histological diagnosis of carcinoma in situ in 1964. "By the date of her discharge in 1979, Ruth had visited National Women's Hospital 34 times, she had had 28 cervical smears, five biopsies, four operations under GA, and 10 colposcopic examinations. But as the final histology clearly showed she still had cancer [carcinoma in situ]." In 1985 "Ruth" had returned to the National Women's Hospital with invasive cervical cancer.

Coney and Bunkle also described efforts by McIndoe and McLean to have this method of management reconsidered, leading to an internal hospital inquiry. They alleged that the report of that inquiry was termed a "white wash" by the then hospital superintendent. Further, Coney and Bunkle claimed that no one could give them an assurance that the study had ever ended. They quoted Professor Bonham, the professor of obstetrics and gynaecology, head of the postgraduate school, and chairman of the hospital ethics committee, as saying that the study "merged into general treatment. It stopped being a study and became general treatment." They also suggested that the views held at the National Women's Hospital had resulted in an attitude of neglect for cervical screening in New Zealand, and consequently a rise in the incidence of and mortality from cervical cancer in young women.

\section{The judicial inquiry}

The inquiry was set up by the Minister of Health at the request of the Auckland Hospital Board and in 
response to public concern about the allegations made in the magazine article. The Minister of Health directed Judge Cartwright to inquire into the specific allegations made in the magazine about the research programme and treatment of women with carcinoma in situ and also more generally into the procedures observed currently at the hospital for the approval and surveillance of research and treatment; into the information made available to patients; and into teaching about the treatment of carcinoma in situ and the value of cervical screening.

\section{FINDINGS}

Judge Cartwright found that a research programme into the natural course of carcinoma in situ of the genital tract had been approved in 1966 and that it had resulted in the failure to treat adequately several women with carcinoma in situ. ${ }^{2}$ For a minority of women their management had resulted in persisting disease, the development of invasive cancer, and in some cases death. She found that additional reasons for the failure to treat adequately were the failure to stop the trial as soon as cogent evidence of risk began to emerge and the failure of some colleagues and administrators to impinge on clinical freedom and act decisively in the interests of the safety of patients.

The research programme had included the 1966 trial and the studies of vaginal cytology in the newborn and of the histology of fetal cervices. The great majority of patients did not know that they were participants in the 1966 trial. The trial had been reviewed by the hospital medical committee in 1975, following expressions of concern, but had never formally been ended.

A review was undertaken for Judge Cartwright of the case notes of patients with carcinoma in situ treated at the hospital. Several women were recommended for further advice or treatment. The National Women's Hospital ethical committee procedures were found to be inadequate and to lack impartiality. The judge recommended that the ethical committee should be disbanded.

The recommendations to improve the protection of patients participating in research or treatment included the appointment of a patient advocate at the National Women's Hospital whose only duty would be to protect the patient to ensure that she received full information and the opportunity to consent to all procedures in which she might participate. In addition, the appointment of a health commissioner under the Human Rights Commission Act was also recommended to negotiate and mediate in complaints and grievances by patients and to heighten the understanding by health professionals of patients' rights.

Improvements in teaching by staff at the National Women's Hospital on the value of cervical screening were also recommended, as was the implementation of an organised screening programme for the whole country.

\section{Ethical issues}

Should a study of the natural history of carcinoma in situ of the genital tract, which entailed withholding generally accepted treatment from patients, have been approved by the hospital medical committee in 1966?

The hospital medical committee was empowered to make decisions about ethical matters relating to research and treatment. At the least the committee members might have been expected to consider the scientific basis of the proposal, to assess the inherent risks in comparison with the foreseeable benefits, and to consider the qualifications of the medical staff to undertake the study. These are basic principles included in the Declaration of Helsinki of $1964 .{ }^{4}$
The argument given in Green's publications for starting the study was that the invasive potential of carcinoma in situ was not proved. He argued that in the earlier studies of untreated carcinoma in situ, in which some cases had progressed to invasion, it had not been possible to rule out the presence of invasion at the outset. ${ }^{5}$ Other contemporary authors also considered this a difficulty. ${ }^{67}$ Green proposed to get around the problem by using colposcopy and colposcopically directed punch biopsies to exclude invasion at the outset. He was also confident that invasion had been excluded in those women whom he proposed to follow who had positive cytological results after either a hysterectomy or cone biopsy for carcinoma in situ.

The proposal presented by Green to the hospital management committee in 1966 stated: "It is considered that the time has come to diagnose and treat by lesser procedures than hitherto a selected group of patients with positive (A3-A5) smears. Including the four 1965 cases there are at present under clinical, colposcopic, and cytological observation eight patients who have not had a cone or ring biopsy. All of these continue to have positive smears at intervals. It is suggested that this should be extended to include all cases in women under the age of 35 with positive smears in which there is no clinical or colposcopic evidence of invasive cancer." 8 The proposal also included a brief justification of the change in management. Green reported on the treatment of women before 1966: 503 women had been treated, 340 of them by cone biopsy or lesser procedure, and many had had persistently positive smears after initial management. He mentioned that one doubtful case was alleged to have progressed to invasion and stated that "one such case is approaching the expected incidence of invasive cervical cancer in any 500 women of this age group." $\mathrm{He}$ also justified the proposal on the apparent failure of screening to influence favourably the incidence of and mortality from invasive cervical cancer.

The written proposal did not include any information about earlier studies by other workers of untreated carcinoma in situ ${ }^{8.10}$ or about the indirect pathological and epidemiological evidence linking carcinoma in situ and invasive cancer. The crucial role of colposcopy was also not explained in the written proposal. There was an assessment of the risks from the early results of the study, which was clearly already in operation. This information, although reassuring, was incorrectly described. The denominator for the proportion progressing to invasion should have included only those women being followed who had positive smears-a figure not given in the proposal, but which was probably 32 from Green's paper. "The corresponding potential benefits of lesser surgical procedures were not mentioned.

At the senior medical staff meeting preceding the hospital management committee meeting the colposcopist, McIndoe, had tabled a memorandum and spoken against the proposal. (The tabling of this memorandum was disputed at the public hearings, but the judge in her report found as a fact that McIndoe had done this.) McIndoe had said: "in the present case inadequate tissue diagnosis, which can be the only description of the type of biopsy I at present perform (if this is to be the only biopsy done), and follow up only taking further steps if there is clinical or colposcopic evidence of invasion, would seem to me the type of care that should not be followed" (McIndoe's private papers, exhibit 75, cervical cancer inquiry).

On the basis of an assessment of hazard to the patient there are grounds for concluding that the project should not have been approved. Earlier similar studies had shown that there was a known risk to the patient of invasive cancer occurring. ${ }^{8.10}$ If Green was right and that risk arose because invasion had been missed at the 
outset in other studies the ability of the colposcopist to rule out invasion with colposcopically directed punch biopsies was crucial. In fact, the newly trained colposcopist was not confident of having this ability; thus a second risk-that an invasive cancer might be overlooked-was added to the first, that an in situ cancer might progress to invasion.

Despite this conclusion, that the proposal represented hazards to the patients outweighing the benefits of lesser surgery, the hazards need not have been very great if the trial had been appropriately monitored and finished. The aim of the study, as stated in the minutes, was "to prove that CIS [carcinoma in situ] is not a premalignant disease" (exhibit 6 , cervical cancer inquiry). Green had set up a study in which he had the opportunity to disprove his hypothesis. Should one case occur in which invasive cancer developed the hypothesis would be disproved, the study stopped, and the remaining patients treated. Should no cases develop invasion many women would be spared major surgery. Moreover, all the trouble, morbidity, and expense of screening and treating women could be abandoned in New Zealand and elsewhere. The importance of the objectives of the research might almost have been said to be in proportion to the risks. ${ }^{4}$

\section{Should consent have been sought from the patients to be} part of such a study?

It was suggested early in the inquiry by a medical ethicist, Alastair Campbell, who was called as an expert witness, that the balance of risks and benefits was the overriding consideration, more important than consent. Thus if the risks were regarded as unacceptable it would be inappropriate to seek the consent of patients; the research should not proceed (transcript of evidence, cervical cancer inquiry). Nevertheless, Beecher in his discussion of consent to clinical experimentation had stated that "the final decision as to the degree of acceptable risk belongs to the subject" and further "some studies bearing moderate risk may be entirely ethical when fully informed consent is obtained, but are otherwise unethical." ${ }_{12}$

Clearly the subject can make this decision only if information on the risks of participation is presented accurately and fairly. If clinical research carrying moderate risk is to proceed it should do so only with the informed consent of the subject. The practice of seeking such consent to clinical experimentation was endorsed by the 1964 Helsinki declaration, which recommended that "if at all possible consistent with patient psychology, the doctor should obtain the patient's freely given consent after the patient has been given a full explanation." ${ }^{4}$ Consent to non-therapeutic research had already been regarded as essential, but the Helsinki declaration provided for exceptions where on occasion consent might not be sought for therapeutic research.

Some of those who have argued against universal informed consent for therapeutic experimental research have done so on the grounds that similar disclosure should obtain for a trial as for ordinary treatment. For example, Doll has written that "so long as physicians limit trials to situations in which they genuinely do not know what is the best way to treat patients, weighing potential risks against benefits, it is, I believe, frequently undesirable to be explicit about the nature of the trial, just as the doctor who is not carrying out a trial is normally not explicit about all the uncertainties associated with the treatment he prescribes." ${ }_{13}^{3}$ Others have argued that full understanding before consent may be so difficult to secure that in certain cases there is no such thing as genuinely informed consent. ${ }^{14}$

But the situation described above by Doll does not apply to the circumstances at the National Women's
Hospital. The National Women's Hospital trial concerned women who had been screened by cervical cytology and referred by their general practitioners because of abnormal findings for the express purpose of treatment at the preinvasive stage. The trial did not entail two alternative treatments, but the withholding of treatment from some women. The implicit ethical undertaking when women had been offered screening was that there should be some benefit to them in detecting an abnormality. ${ }^{15}$ In addition, there were acknowledged risks of non-treatment potentially greater than those of treatment, so that the decision to allow a deviation from accepted treatment carried a responsibility to inform the patients that they were not being offered the generally accepted treatment, of the risks which this entailed, and of the alternatives available. I do not believe that whether the deviation had a research aim or not should alter this conclusion. Moreover, information about lack of treatment was absolutely vital for follow up. Some women were lost to follow up, apparently unaware that they had not been treated, and presented later with symptoms of invasive cancer.

\section{Was the study monitored adequately?}

I have argued that it was crucial to the safety of the patients that the trial should have been stopped as soon as the first cases of invasive cancer were found. Therefore monitoring the results of the study was vital. Even in recent years it has not been usual for ethics committees to monitor projects after they have been approved. ${ }^{16}$ Responsibility for monitoring studies has fallen to the individual investigators. Nevertheless, monitoring the results of clinical trials and determining in advance the criteria for stopping a trial have been recommended practice. ${ }^{17}$ The original proposal by Green did not spell out any criteria for terminating the trial. Nevertheless, his colleagues would have expected him to publish progress reports on his study as he had done before 1966. Such reports might have been expected to document any subsequent diagnoses of invasion. The publications up to and including $1970^{18-21}$ reported no further cases of progression to invasive cancer among women followed who had positive smears. Green's next publication in 1974 reported six cases progressing to invasion out of 96 followed with positive cytological results for at least two years. ${ }^{22}$

At this point, and indeed earlier, the trial had accomplished its aim. It had shown that carcinoma in situ in some cases was a premalignant disease; with no way of knowing which cases would become invasive all would need treatment. Green himself, however, drew a different conclusion at this time. He argued that the trial was not capable of disproving his hypothesis. In the 1974 paper he suggested that his earlier conclusion that "the risk of invasion in untreated or under-treated CIS [carcinoma in situ] was small and possibly much the same as in the total female population" was perhaps overstated not because of the occurrence of invasive cancers but "mainly because of the inability of present methods to exclude adequately invasive cancer at the outset." ${ }^{27}$ Hence Green concluded that at least some of the cases may have been missed invasive cancers. Although this cannot be ruled out as an explanation, it has no relevance to the risk to the patients. If it was not possible to be sure by limited biopsy at that time which cases were invasive then I believe that all should have been offered accepted treatment. Green seems never to have made this link in his reasoning. No comment was made in the paper to suggest that the trial had been ended.

At the National Women's Hospital monitoring by the investigator failed. Nevertheless, the published papers made the results of the study available to academic and clinical colleagues. By 1974 Green 


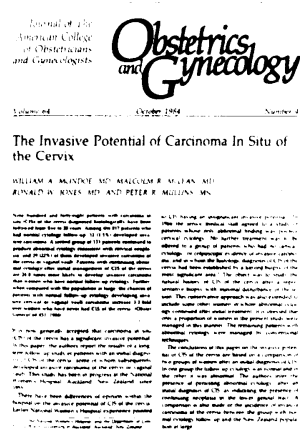

.... - himself had reported cases of progression. It was possible for his senior academic and administrative colleagues to review the outcome of the study themselves and require that it be ended.

In fact the closest monitoring of the trial did come from his colleagues, McIndoe and McLean, who as colposcopist-cytologist and pathologist saw the results directly. The formal expressions of concern raised by McIndoe and McLean preceded the publication of the 1974 paper. Nevertheless, their monitoring produced results different from those reported by Green-for example, their formal letters to the medical superintendent included details of more patients followed who had positive cytological results before a diagnosis of invasive cancer than were mentioned in the 1974 paper (exhibits 127 and 128, cervical cancer inquiry). It seems likely that Green excluded these further patients from his publications because he reviewed the original diagnoses and reclassified the cases as invasive at the outset. Ralph Richart, commenting on this as an expert witness at the inquiry, said: "Dr Green has stated in his brief, that it was obviously impossible to exclude invasion in some patients. This is given as a reason for retrospectively excluding them from the study. This creates three problems. It introduces an unacceptable bias that militates against ever having a valid study; it allows the investigator to influence the outcome of the study by introducing his preconceptions (even if unconsciously); and, most importantly, it indicates that the entry criteria are such that a significant number of women will be followed prospectively as carcinoma in situ patients who actually have invasive cancer-a potentially fatal disease. That discovery once made, requires in my opinion that the study be terminated" (transcript of evidence, cervical cancer inquiry).

If investigators draw faulty inferences from their own data or abandon usual scientific conventions it is extremely difficult for outsiders to monitor a study satisfactorily. Nevertheless, there were opportunities for the study to be monitored internally, as was done by McIndoe and McLean. Their concerns culminated in a visit and then letters to the medical superintendent in 1973.

\section{Were the concerns of other doctors acted on?}

The letters written by McIndoe and McLean asked the medical superintendent for a reappraisal of policy towards the management of patients with abnormal findings on cytology and colposcopy. McIndoe listed seven patients whose subsequent clinical course was of concern. These were women subsequently shown to have invasive cancer. He also mentioned a further list of patients with continuing positive cytological findings on follow up who had never had more than limited biopsies performed, in several of whom he believed that more adequate biopsy might have disclosed invasive cancer. The letter from McLean to the medical superintendent raised similar concerns and highlighted the problem of missed invasions: "we are not justified in managing cases of supposed CIS [carcinoma in situ] conservatively unless adequate efforts have been made to exclude invasive carcinoma ... We cannot say for certain, but it is likely that in most of these cases causing concern, invasive carcinoma was present when the patient was first seen." McLean listed 14 cases in which patients originally diagnosed as having had carcinoma in situ were subsequently shown to have invasive carcinoma of the cervix.

The superintendent took the two doctors with their written complaints to his superior, the superintendent in chief of the Auckland Hospital Board. The superintendent in chief referred the matter back to the superintendent, asking that it be investigated within the hospital in the first instance. Green was asked, through Professor Bonham, to reply to the concerns raised by McIndoe and McLean, who in turn responded with further letters. Both doctors described difficulties in reasoning with Green. In 1975 the hospital management committee set up an internal inquiry, but it was given and accepted as its terms of reference "to consider whether the above [1966 policy] had been adhered to" with respect to certain patients (exhibit 29, cervical cancer inquiry). The patients were those noted by McIndoe and McLean. It is not clear from the report that this internal committee of inquiry was shown the original letters from McIndoe and McLean. In its report the committee agreed in general that the policy had been followed; confirmed that the patients had developed invasive disease; expressed ambiguous misgivings about the uncertainties of pathological diagnoses and the inclusion of patients over the age of 35; and recommended that individuals should in future subjugate their personal differences "in the interests of scientific inquiry," (transcript of evidence, cervical cancer inquiry). The report did not recommend that the trial should be ended or that the management of existing patients should be reviewed.

Discussion of the report by the hospital management committee was then delayed for two years. In 1977 the committee asked for further reports from Green, McIndoe, and McLean and in 1978 produced new guidelines for the taking of biopsy specimens.

An internal inquiry had failed entirely to address the central issue: should the policy be reappraised and new and existing patients be treated differently? Despite this failure it seems likely that the management of new patients with carcinoma in situ was modified in consequence of the report of the internal inquiry. The review undertaken for the judicial inquiry showed that the rate of progression to invasion had fallen steeply among those cases of carcinoma in situ first diagnosed after 1975 compared with the rate for those diagnosed in the previous five years. Nevertheless, many patients diagnosed before 1975 continued untreated. ${ }^{2}$

There are several arguments for the need to have investigated properly the complaints of McIndoe and McLean. Firstly, the safety of hospital patients was alleged to have been at risk. Secondly, the persons expressing concern were senior doctors, who because of the nature of their work were best placed to know what was happening in the management of patients with carcinoma in situ. Thirdly, the doctors had followed proper procedures in making their concerns known to the medical superintendent.

After 1975 McIndoe and McLean, together with gynaecologist Ron Jones, started to make public the results of the trial at scientific conferences and meetings held at the hospital. Many gynaecologists around the world were undoubtedly already familiar with Green's studies as he had published openly and travelled to international meetings to present his work. Despite this widespread knowledge no attempts seem to have been made from outside New Zealand to intervene, except by a Norwegian gynaecologist, Per Kolstad. He visited the National Women's Hospital in 1973 , disagreed with Green over his management of certain patients, and supported McIndoe's action (transcript of evidence, cervical cancer inquiry).

The editor of Obstetrics and Gynecology encouraged McIndoe, McLean, and Jones to write up the results for publication. This culminated in the publication of the papers on carcinoma in situ of the cervix in 1984 and on carcinoma in situ of the vulva in $1986 .{ }^{23}$ Even though the authors had taken the 1984 paper to the new medical superintendent before publication, and even though it documented some patients still being followed with persistent carcinoma in situ, no action was taken by the superintendent; the study was never formally stopped. 


\section{Underlying issues}

SCIENCE

A supporter likened Green to Semmelweiss, a great scientist who was pilloried by his uncomprehending colleagues (exhibit 63, cervical cancer inquiry). His professor described him as "a unique sort of free thinker." It is the notion of a scientist not only as an original thinker but as someone set apart whose activities cannot be understood that may have been responsible for the extent of the damage done at the National Women's Hospital.

That some of Green's colleagues failed to grasp the aim of the trial was evident at the public hearings. Two of his senior colleagues described the aim of the trial, not as "to prove that CIS [carcinoma in situ] is not a premalignant disease" as the minutes recorded, but as "to prove that CIS is not invariably a premalignan disease" (transcript of evidence, cervical cancer inquiry). That such an aim would have been unlikely and more hazardous-because testing it would have entailed following women until all developed invasive cancer-was pointed out by one of the expert witnesses. Not only was there misunderstanding or obfuscation about the aim of the trial: at the same time the view was put forward that there had been no trial but only an attempt to find the best treatment for carcinoma in situ.

A sense of inability to evaluate scientifically the results of the trial was conveyed by one of the members of the 1975 committee of inquiry at the recent public hearings. When asked why the committee had looked only at whether the 1966 proposal had been followed and not whether the proposal needed to be reappraised, he said that such a task would have required an investigation into the outcome for all patients and into the problems of pathological interpretation. "No member of the working party, in my opinion, had that sort of particular expertise in their background."

Interestingly, the doctors who felt able to evaluate and judge Green's work and even write it up for publication came from the non-academic staff. But the response of some other staff, including academics, to the paper was to misunderstand its conclusions. For instance, several staff who gave evidence at the public hearings, concluded from the paper by McIndoe et al that the rate of progression of carcinoma in situ to invasion, must lie between the rate for the untreated or partially treated group and the rate for the successfully treated group (transcript of evidence, cervical cancer inquiry). Furthermore, after publication of that paper no meetings had been organised to discuss the results and their implications for hospital practice. In a climate in which scientific issues are not openly discussed and yet scientists are given a special place, there is danger that the aberrant views of one individual may go unchallenged.

\section{ACCOUNTABILITY}

The Declaration of Geneva requires doctors to affirm that "I will practise my profession with conscience and dignity"; "the health of my patient will be my first consideration"; and "my colleagues will be my brothers." 24 To whom should doctors be accountable first: their own conscience, their patients, or their colleagues? A view implicit in much of the evidence at the public hearings was that a clear conscience would dictate that any doctor would act in the patient's best interests. The retired superintendent in chief of the Auckland Hospital Board emphasised: "This above all-to thine own self be true. And it must follow, as the night the day, thou canst not then be false to any man" (transcript of evidence, cervical cancer inquiry). There was even a reference in the minutes of the meeting at which the 1966 proposal had been approved to
Professor Green, "whose conscience is clear and who could therefore accept complete responsibility for whatever happens. . . ." (hospital medical committee minutes, exhibit 11 , cervical cancer inquiry). But, as anyone familiar with $\mathrm{Hamlet}$ knows, Polonius's advice to Laertes is too facile a view of human nature. You may behave irrationally and yet have a clear conscience.

Of even more concern at the inquiry was that the dictum "my colleagues will be my brothers" had been taken too much to heart. The failure of the hospital and the university authorities to act appropriately after concerns had been raised in 1973 may best be understood as a failure to put the safety of patients before the reputation of colleagues. During the public hearings the notion of clinical freedom was used to defend the actions of colleagues; only illegal actions seemed beyond its scope (transcript of evidence, cervical cancer inquiry). Possibly the situation at the National Women's Hospital is no exception to the way that doctors usually behave. Friedson has argued that the service orientation of the medical profession has been promoted by doctors pursuing their claims for autonomy but that there was little empirical evidence to support this orientation. ${ }^{25}$ Furthermore, he argued that if the profession fails to regulate itself according to that orientation, which ostensibly puts the patients first, and if the public sees that failure the profession risks losing its freedom from lay supervision and control. "The profession's privileged position is given by, not seized from, society, and it may be allowed to lapse or may even be taken away." Since Friedson published this opinion there has been a lot more talk about peer review and medical audit as ways of internally regulating the profession, but little evident action.

\section{WOMEN}

Complaints about the treatment of patients in hospital usually come from the patients themselves. In this case, however, it seems there were no such complaints. Undoubtedly this is partly accountec' ror by the symptomless nature of the initial condition, which had in most cases been detected by routine screening. The women could not gauge the effectiveness of treatment by monitoring their own symptoms in the usual way. Some women had complained to their general practitioners that they were going back repeatedly to the hospital and nothing seemed to be being done (transcript of evidence, cervical cancer inquiry). The general practitioners had been helpful and had referred the woman privately or even got in touch with Dr McIndoe, who had tried to help, but no woman or general practitioner had apparently made a formal complaint to the hospital.

Could men have been in exactly the same position? It seems to me likely that women were more vulnerable at that time to being included in a trial of treatment without their knowledge and consent and more likely to endure such a trial without making formal complaint. Women have been familiar with being patients in many aspects of reproductive function.

The 1960s probably saw the height of the medicalisation of childbirth. The extraordinary patience of women such as "Ruth," who returned to the hospital for an endless series of examinations and biopsies, was possibly conditioned by earlier years of antenatal clinic attendance. I suggest that women were vulnerable because they were used to submitting to medical checks without being told the exact purpose. I consider that they were also vulnerable because they were exposed to examination of the genital area by male doctors; in this situation the asymmetry of power between the doctor and the patient is exaggerated. Finally the sense of trust and good faith that most women had in the hospital and its staff also in my view 
made women vulnerable. Those less trusting women were the ones who went back to their general practitioners and asked for treatment. The most trusting continued to attend. The revelations of the inquiry have damaged this trust and good faith not only in the National Women's Hospital but also elsewhere in New Zealand. Many doctors are extremely perturbed about the new lack of trust. Those doctors need to stop and think. The trust that existed has been shown not only to have been misplaced but to have been dangerous to the women concerned.

I have emphasised the special characteristics of women that might have made them vulnerable to worse treatment than men would have received. Others will point to the behaviour of doctors towards women patients. I suspect that some doctors have treated women with less regard for their autonomy than they have shown to men. But in this women may have shared the experience of men in other less powerful groups: the poor, the old, and the mentally ill.

\section{Conclusions}

I have given reasons for the judge's conclusions that the research proposal should probably not have been approved at the outset; that consent should have been sought from the patients; that the study was not monitored adequately; and that the concerns of other doctors were not acted on. Furthermore, I have argued that the reasons for this failure to protect the safety of patients went beyond the individual researcher and needed to be sought in the attitudes of doctors to science, to accountability, and perhaps to women. How might these broader concerns be addressed?

Firstly, we need to be able to understand the work of clinical scientists. Their colleagues must first understand what they are proposing if there is to be any hope that patients may later be sufficiently informed to decide whether to take part in research. For this there must be more emphasis on the science of medical practice. Studies of the outcome of treatment require applying scientific methods not to how the body works but to how well clinical practice works. For this it is essential to move from the perspective of the individual patient to that of groups or populations. Roberts has suggested that such epidemiological methods need to be understood and used by clinicians: "it is largely through epidemiology that the physician can satisfy the requirements of contemporary society, which expects him to be scientific (as distinct from technically competent) about what he is doing compared with formerly when society was satisfied that he was scientific about what he was looking at." ${ }^{26}$

The public's scepticism and distrust of the scientist and the researcher in medicine may be due to an overemphasis on understanding mechanisms and on developing new technology and to a neglect for evaluating the outcome of treatments. The emphasis needs to be shifted. Paradoxically, New Zealand medical scientists are concerned that publicity about the study at the National Women's Hospital may make research more difficult to undertake because of public distrust or bureaucratic overregulation. I believe distrust will be an unavoidable consequence of the inquiry, but it would be folly to blame the publicity itself and not the real problems it disclosed.

Will the interests of patients be safeguarded in future by the profession reasserting its commitment to medical audit? The debate seems to have reached an impasse. The reason given by the profession for medical audit is almost always as a means to satisfy the public in order to ward off "regulation from outside the profession that will severely curtail our clinical freedom." 27 If there are real reasons why the public wants to curtail clinical freedom-and this inquiry suggests that there are-the profession should be as concerned as the public. Would a truly service orientation result in such reluctance to form an alliance with the public to improve the safeguards for patients? The profession is already losing some of its autonomy from lay supervision and control in New Zealand, as was shown by the establishment of a committee of one lay person to inquire into the National Women's Hospital allegations.

There are dangers in control by the laity: an overemphasis on the easily quantifiable, especially cost; unfamiliarity with the technical and scientific aspects of medicine; and ignorance of the uncertainties on which clinical judgment is often based. Surely some of these difficulties could be overcome by bringing the public and the profession closer together? The public needs to understand that mistakes are common in medicine, and are often inevitable. McIntyre and Popper have called for a new ethics to allow the profession to acknowledge and deal with error ${ }^{28}$ They recommend a new critical attitude in medicine-to one's own work and to that of others. But this requires tolerance; "in the search for mistakes there should be no denigration of others." Condemnation would then be properly reserved for those who sought to cover up error.

Inevitably, new consent procedures will be recommended, especially for patients concerned in research and teaching. In the past the principal safeguard for the patient has been the integrity and good faith of the doctor. When that good faith is brought into question at the highest levels in the hospital there must be recourse to other mechanisms to protect the patient. Patients will welcome more information and a greater chance to make informed decisions about their treatments, but I suspect that both doctors and patients will continue to worry about the lack of trust. People who are ill need to be able to trust their medical advisers, but that trust is not bestowed with a higher degree; if it has been abused it will need to be earned again.

It is tempting to imagine that the increasing proportion of women in medicine will change professional attitudes. Women gynaecologists have the advantage that they are familiar with some of the experiences of their women patients. But I know no reason to believe that women are not otherwise as fallible as men in every aspect of medical practice.

1 Coney S, Bunkle P. An "unfortunate experiment" at National Women's. Metro 1988 June:47-65.

2 Cartwright SR. The report of the committee of inquiry into allegations concerning the treatment of cervical cancer at National Women's Hospital and into other related treatment of cervical cancer at National Women's Hospital

3 McIndoe WA, McLean MR, Jones RW, Mullen PR. The invasive potential of McIndoe WA, McLean MR, Jones RW, Mullen PR. The invasive
carcinoma in situ of the cervix. Obstet Gynecol 1984;64:451-8.

4 World Medical Association. Human experimentation. Code of ethics of the World Medical Association. Declaration of Helsinki. Br Med f 1964;ii: 177 5 Green GH. Is cervical carcinoma in situ a significant lesion? Int Surg 1967;47:511-7

6 Boyes DA, Fidler HK, Lock DR. Significance of in situ carcinoma of the uterine cervix. Br Med f 1962;i:203-5.

Knox EG. Cervical cytology: a scrutiny of the evidence. In: McLachlan G, ed. Problems and progress in medical care. 2nd series. London: Nuffield Provincial Hospitals Trust, 1966:279-309.

8 Koss LG, Stewart FW, Foote FW, Jordan ML, Bader GM, Day E. Some histological aspects of behaviour of epidermoid carcinoma in situ and related lesions of the uterine cervix. A long term prospective study. Cancer lesions of the uterin
$1963 ; 9: 1160-211$.

9 Petersen O. Spontaneous course of cervical precancerous conditions. Am $\mathcal{J}$ Obstet Gynecol 1956;72:1063-71.

10 Kottmeir HL. Carcinoma of the female genitalia. Baltimore, Williams and Wilkins, 1953.

11 Green GH. Pregnancy following cervical carcinoma in situ. Journal of Obstetrics and Gynaecology of the British Commonwealth 1966;73:897-902.

12 Beecher HK. Research and the individual: human studies. Boston: Little, Brown, 1970 .

13 Doll R. Clinical trials: retrospect and prospect. Stat Med 1982;1:337-44.

14 Hill AB. Medical ethics and controlled trials. Br Med f 1963;i:1043-9.

15 McKeown T (chairman). Validation of screening procedures. In: Screening in medical care. London: Nuffield Provincial Hospitals Trust, 1968:1-13.

16 Howard-Jones N, Bankowski Z, eds. Medical experimentation and the protection of human rights. Proceedings of the XII th Council for International Organizations of human rights. Proceedings of the XIIth Council for International
of Medical Sciences round table conference. Geneva: CIOMS, 1979.

17 Medical Research Council for New Zealand. Project and programme grants. Auckland: Medical Research Council of New Zealand, 1986. 
18 Green GH. Invasive potentiality of cervical carcinoma in situ. Int $\mathcal{f}$ Gynaecol Obstet 1969;7:157-71.

19 McIndoe WA, Green GH. Vaginal carcinoma in situ following hysterectomy. Acta Cytol 1969;13:158-62.

20 Green GH, Donovan JW. The natural history of cervical carcinoma in situ. Fournal of Obstetrics and Gynaecology of the British Commonwealth 1970;77 1-9.

21 Green GH. Cervical carcinoma in situ. Aust N Z J Obstet Gynaecol 1970;10 $41-8$

22 Green GH. The progression of pre-invasive lesions of the cervix to invasion. New Zealand Medical foumal 1974;80:279-87.
23 Jones RW, McLean MR. Carcinoma in situ of the vulva: a review of 31 treated and five untreated cases. Obstet Gynecol 1986;68:499-503.

24 British Medical Association. The handbook of medical ethics. London: BMA $1984: 70$.

25 Freidson E Profession of medicine. New York: Dodd, Mead, 1972

26 Roberts CJ. Epidemiology for clinicians. Kent: Pitman Medical, 1977.

27 Hoffenberg R. The Rock Carling fellowship 1986, clinical freedom. London Noffenberg R. The Rock Carling fellowship
Nuffield Provincial Hospitals Trust, 1987.

28 McIntyre N, Popper K. The critical attitude in medicine: the need for a new ethics. BrMed f 1983;287:1919-23.

\title{
Lesson of the Week
}

\section{Brain abscess complicating cervical traction}

\author{
A T Reece, N V Todd
}

Skull tongs and callipers that lack a mechanism for limiting depth of penetration of bone are associated with a definite risk of brain abscess and should be abandoned

Institute of Neurological

Sciences, Southern General Hospital, Glasgow G51 4TF

A T Reece, FRCS, registrar in neurosurgery

$\mathrm{N}$ V Todd, FRCS, senior neurosurgical registrar

Correspondence to: Mr Todd.
Patients with a diagnosis of fracture-dislocation of the cervical spine must have their fracture immobilised immediately. Traction can be applied with skull tongs and various types are used. We report two cases of brain abscess complicating the use of Cones callipers.

\section{Case reports}

Case 1-A 66 year old man sustained a fracturedislocation of C4-5, which was treated orthopaedically by traction for seven weeks with the use of Cones callipers. Five months later a right temporal osteomyelitis developed and sequestrectomy was performed under local anaesthesia. Seven months after that procedure the patient was admitted to the regional neurosurgery unit with headache, drowsiness, left hemiparesis, and a fever of $38.5^{\circ} \mathrm{C}$. Computed tomography (CT) showed multiple abscesses in the right temporal lobe; the neck was stable. The abscesses were excised at craniotomy. Culture disclosed a heavy growth of Staphylococcus aureus, and benzylpenicillin and chloramphenicol were started. The hemiparesis resolved by the second postoperative day.

Case 2-A 52 year old man suffered a fracturedislocation of C6-7. This was treated by skull traction with use of Cones callipers. Three weeks later he began to have focal seizures affecting the face and arm and increasing drowsiness. Radiographs and CT of the cervical spine showed the fracture to be stable, and CT in the regional neurosurgery unit disclosed an abscess in the right temporal lobe. This was drained through a small craniectomy, and culture grew Staph aureus. Chloramphenicol and benzylpenicillin were given, and by the 10th postoperative day the patient was alert and had minimal drift of the left arm.

\section{Discussion}

Brain abscess has been reported in 13 patients treated with skull tongs ${ }^{1-4}$ and two treated with halo fixators. ${ }^{5}$ The diagnosis may not be obvious and a high level of suspicion is required; five of the 13 patients quoted above died. The abscess may be preceded by local osteomyelitis of the skull, for which limited sequestrectomy or antibiotics, or both, are rarely adequate.

All the reported cases of brain abscess occurred after the use of tongs that lacked a mechanism for limiting the depth of penetration into the skull. In 12 of the 13 cases there was a definite breach in the inner table. In six, however, the dura was found to be intact at exploration, suggesting that penetration of bone was the relevant factor. There have been no cases of abscess reported after the use of Gardner-Wells tongs, which have a spring loaded mechanism that prevents penetration of the inner table of the skull (table). Cones callipers lack this mechanism. They and similar types of skull tongs should no longer be used.

We thank Mr S L Galbraith and Professor G M Teasdale for permission to report these cases.

1 Harris P, Win PHT. The management of patients with injury of the cervical spine using Blackburn skull calipers and the Stryker turning frame. spine using Blackburn sk

2 Jamieson KG, Yelland JDN. Cerebral abscess due to skull traction. Aust $N Z \mathcal{J}$ Surg 1965;34:301-2.

3 Weisl $\mathrm{H}$. Unusual complications of skull caliper traction. F Bone Joint Surg [Br] 1972;54:143-5.

4 Hall JC, Burke OC. Brain abscess following the insertion of skull tongs. Paraplegia 1979;17:278-9.

5 Dennis GC, Clifton GL. Brain abscess as a complication of halo fixation. Neurosurgery 1982;10:760-1.

(Accepted 25 May 1988)

Mechanisms of skull tongs in common use and list of those that should be abandoned

$\left.\begin{array}{llll}\hline \multicolumn{1}{c}{\text { Type of tongs }} & \multicolumn{1}{c}{\text { Mechanism }} & \multicolumn{1}{c}{\text { Comments }} & \text { Recommended for use } \\ \hline \begin{array}{l}\text { Gardner-Wells } \\ \text { Cones callipers }\end{array} & \text { Spring loaded, 13.6 kg pressure } & \text { Does not penetrate inner table of skull } \\ \text { Ice tongs } & \text { Screw thread } & \text { Tightened by hand; no limit to depth of penetration } \\ \text { Crutchfield tongs } & \text { Tong inserted into twist drill hole } & \begin{array}{l}\text { Inner table may be penetrated by twist drill or subsequent } \\ \text { tightening of tongs } \\ \text { Dura always exposed }\end{array} & \text { Yes } \\ \text { Blackburn callipers } & \text { Tong inserted into standard burr hole } & \text { No } & \end{array}\right\}$

Risk of infection of central nervous system is present when dura is exposed, greatest when dura is penetrated. 